\title{
Is There a Precise Correlation between the Lengths of the Peritoneal Reflection and the Middle Rectal Valve?
}

\author{
Isaac José Felippe Corrêa Neto ${ }^{10}$ Mariana Campello de Oliveira ${ }^{2(1)}$ Laercio Robles $^{3(0)}$ \\ Leonardo Marcos Lopes Santos ${ }^{4(1)}$ Alexander Sá Rolim ${ }^{1}$ Rogério Freitas Lino Souza ${ }^{10}$ \\ Hugo Henriques Watté ${ }^{1}$ Angelo Rossi da Silva Cecchini ${ }^{10}$
}

\footnotetext{
${ }^{1}$ Coloproctology Assistant Physicians from Faculdade de Medicina Santa Marcelina, São Paulo, SP, Brazil

2 Graduated from Faculdade de Medicina Santa Marcelina, São Paulo, SP, Brazil

${ }^{3}$ Department of General Surgery and Coloproctology Service,

Faculdade de Medicina Santa Marcelina, São Paulo, SP, Brazil

${ }^{4}$ General Surgery Resident Physician of the Hospital Santa Marcelina,

São Paulo, SP, Brazil
}

J Coloproctol 2022;42(2):115-119.

Address for correspondence Isaac José Felippe Corrêa Neto, MD, PhD, Coloproctology Assistant Physicians from Santa Marcelina School of Medicine, São Paulo, Brazil (e-mail: isaacneto@hotmail.com).

\begin{abstract}
\section{Keywords}

- peritoneal reflection

- rectal valve

- rigid sigmoidoscopy

- obesity

- parity

Introduction Pelvic anatomy remains a challenge, and thorough knowledge of its intricate landmarks has major clinical and surgical implications in several medical specialties. The peritoneal reflection is an important landmark in intraluminal surgery, rectal trauma, impalement, and rectal adenocarcinoma.

Objectives To investigate the correlation between the lengths of the middle rectal valve and of the peritoneal reflection determined with rigid sigmoidoscopy and to determine whether there are any differences in the location of the peritoneal reflection between the genders and in relation to body mass index (BMI) and parity.

Design We prospectively investigated the location of the middle rectal valve and of the peritoneal reflection via intraoperative rigid sigmoidoscopy in colorectal cancer patients undergoing elective colorectal surgery.

Results We evaluated 38 patients with a mean age of 55.5 years old ( $57.5 \%$ males) who underwent colorectal surgery at the coloproctology service of the Hospital Santa Marcelina, São Paulo, state of São Paulo, Brazil. There was substantial agreement between the lengths of the middle rectal valve and of the peritoneal reflection $($ Kappa $=0.66)$. In addition, the peritoneal reflection was significantly lower in overweight patients ( $p=0.013$ for women and $p<0.005$ for men) and in women with $>2$ vaginal deliveries $(p=0.009)$, but there was no significant difference in the length of the peritoneal reflection between genders $(p=0.32)$.

Conclusion There was substantial agreement between the lengths of the peritoneal reflection and of the middle rectal valve, and the peritoneal reflection was significantly lower in overweight patients and in women with more than two vaginal deliveries.
\end{abstract}

received

April 26, 2021

accepted after revision

October 25, 2021

published online

January 17, 2022
DOI https://doi.org/

10.1055/s-0041-1739550.

ISSN 2237-9363. (c) 2022. Sociedade Brasileira de Coloproctologia. All rights reserved.

This is an open access article published by Thieme under the terms of the Creative Commons Attribution-NonDerivative-NonCommercial-License, permitting copying and reproduction so long as the original work is given appropriate credit. Contents may not be used for commercial purposes, or adapted, remixed, transformed or built upon. (https://creativecommons.org/ licenses/by-nc-nd/4.0/)

Thieme Revinter Publicações Ltda., Rua do Matoso 170, Rio de Janeiro, RJ, CEP 20270-135, Brazil 


\section{Introduction}

Pelvic anatomy remains a challenge for the surgeon. The pelvis contains intestinal, urological, gynecological and vascular organs, and neural structures enclosed in the musculoskeletal space, which requires a great deal of expertise, with major clinical and surgical implications in several medical specialties. ${ }^{1}$

The rectum and its relations to the pelvis and to the peritoneal reflection are of considerable clinical significance - and although the word rectum comes from the Latin rectum, meaning straight, in humans it is a tubular structure that has curves adapting to the shape of the sacrum and of the coccyx. ${ }^{2,3}$ Both the proximal and distal limits of the rectum are controversial: the rectosigmoid junction is considered by surgeons to be located at the sacral promontory, but at the level of the third sacral vertebra by anatomists, and the distal limit is considered by surgeons as being the muscular anorectal ring, and the dentate line by anatomists. Moreover, the transition from the sigmoid colon to the rectum is a useful landmark characterized by the absence of taeniae and epiploic appendices. ${ }^{2-6}$

The rectum has lateral curves that provide useful anatomic landmarks in relation to the anal verge. These curves correspond intraluminally to the folds or valves of Houston. The 2 left-sided folds are usually observed at between 7 and $8 \mathrm{~cm}$ and at between 12 and $13 \mathrm{~cm}$ from the anal verge, respectively, and the one on the right is generally at between 9 and $11 \mathrm{~cm}$. The middle valve (Kohlrausch plica) is the most consistent in location and corresponds to the level of the anterior peritoneal reflection, which is lower in females. ${ }^{1,7}$

However, the number and location of these valves may vary; roughly $46 \%$ of patients have 3 valves, 33\% have $2,10 \%$ have $4,2 \%$ have none, and the remaining percentage has from 5 to 7 valves. $^{8}$

The upper third of the rectum is anteriorly and laterally invested by peritoneum; the middle third is covered by the peritoneum on its anterior aspect only, and the lower third of the rectum is entirely extraperitoneal. Thus, these curves and reflections can increase resection margins during rectal mobilization by up to $5 \mathrm{~cm}^{9}$

The length of the peritoneal reflection is an important anatomic landmark in intraluminal surgery, intra- or extraperitoneal rectal trauma, ${ }^{10}$ penetrating trauma caused by gunshot wounds, stab wounds or impaling objects, and rectal adenocarcinoma amenable to neoadjuvant therapy. ${ }^{11}$

In the present study, we aimed to investigate the correlation between the lengths of the middle rectal valve and the peritoneal reflection determined via rigid sigmoidoscopy and to determine whether there are any differences in the location of the peritoneal reflection between genders and in relation to body mass index (BMI) and parity.

\section{Materials and Methods}

\section{Patients and Study Design}

We prospectively investigated the location of the middle rectal valve and of the peritoneal reflection via intra- operative rigid sigmoidoscopy in colorectal cancer patients who underwent abdominal colorectal surgery at the coloproctology service of the department of general surgery of the Hospital Santa Marcelina (HSM, in the Portuguese acronym), São Paulo, state of São Paulo, Brazil.

Laparotomy was performed with the patient in the LloydDavies position and the distance from the anal verge to the middle rectal valve and to the anterior peritoneal reflection was measured using a rigid sigmoidoscope with the surgeon accurately determining the location of the peritoneal reflection.

The exclusion criteria were history of pelvic surgery, symptoms of fecal incontinence, inability to accurately locate the middle rectal valve via rigid sigmoidoscopy due to tumor infiltration or stenotic lesions, and unwillingness to provide written consent to participate in the study.

The following variables were evaluated: gender, age, weight, height, BMI, body type, parity, preoperative radiotherapy, and the lengths of the middle rectal valve and of the peritoneal reflection.

\section{Statistical Analysis}

The Student $t$-test and the Fisher exact test were used for univariate analysis of BMI, gender, parity, body type, and length of the peritoneal reflection and of the middle rectal valve. Data were considered statistically significant if $p<0.05$, with a $95 \%$ confidence interval (CI), and all analyses were performed using IBM SPSS Statistics for Windows, version 22.0 software (IBM Corp., Armonk, NY, USA).

\section{Results}

Forty patients with a mean age of 55.5 years old (range: 30 84 years old) underwent colorectal surgery at the coloproctology service of the HSM over a 4-month period. Twentythree patients (57.5\%) were men and $94.1 \%$ of the women had an obstetric history, with an average of 3.4 children (range: 1-7 children). The tumors were distributed equally on the right colon (32.5\%), in the left colon (35\%), and in the rectum (32.5\%).

Nineteen patients (47.5\%) had no comorbidities and 7 (17.5\%) had diabetes mellitus. Six patients (15\%) received neoadjuvant therapy for nonstenosing middle and low rectal cancers.

The mean weight of the patients was $70.75 \mathrm{~kg}$ (range: $40-130 \mathrm{~kg}$ ), and their mean height was $164 \mathrm{~cm}$ (range: $140-182 \mathrm{~cm}$ ), for a mean BMI of $26.05 \mathrm{~kg} / \mathrm{m}^{2}$ (range, 13.9 $40.4 \mathrm{~kg} / \mathrm{m}^{2}$ ).

When the height of the middle rectal valve in a cut of $8.0 \mathrm{~cm}$ in relation to the anal margin was analyzed, it was observed that it was significantly lower in patients with BMI $>25 \mathrm{~kg} / \mathrm{m}^{2}$ of both genders, and the difference was more pronounced in male $(p<0.005)$ than in female $(p=0.013)$ patients ( - Table 1 ). In addition, the peritoneal reflection was significantly more caudal in women with $>2$ vaginal deliveries $(n=15$; median height of the middle valve $=10.8 \mathrm{~cm}$ ) than in women with $<2$ deliveries $(n=2$; median height of the middle valve $=9.0 \mathrm{~cm})(p=0.009)$. 
Table 1 Correlation between the height of the middle rectal valve and body mass index

\begin{tabular}{|l|l|l|}
\hline & BMI $<24.9 \mathrm{~kg} / \mathrm{m}^{2}$ & BMI $>25.0 \mathrm{~kg} / \mathrm{m}^{2}$ \\
\hline $\begin{array}{l}\text { Middle rectal } \\
\text { valve } \leq 8 \mathrm{~cm}\end{array}$ & 0 patients & 6 patients \\
\hline $\begin{array}{l}\text { Middle rectal } \\
\text { valve }>8 \mathrm{~cm}\end{array}$ & 27 patients & 7 patients \\
\hline
\end{tabular}

Abbreviation: BMI, body mass index.

The mean lengths of the middle rectal valve and of the peritoneal reflection were $9.57 \mathrm{~cm}$ and $11.02 \mathrm{~cm}$, respectively, and in 7 patients (17.5\%) the 2 landmarks had the same length. The peritoneal reflection could not be measured in one patient due to tumor invasion.

There was substantial agreement $($ Kappa $=0.66,95 \% \mathrm{CI}$ : $0.69-0.184$ ) between the lengths of the peritoneal reflection and of the middle rectal valve determined with the rigid sigmoidoscope before and after laparotomy, although the sensitivity between measurements was $56.4 \%$ with a difference margin of $1 \mathrm{~cm}$.

The distribution of patients with equal measurements for the peritoneal reflection and the middle rectal valve was similar between genders. The mean lengths of the middle rectal valve and of the peritoneal reflection were $9.53 \mathrm{~cm}$ (range: $7-11 \mathrm{~cm}$ ) and $10.59 \mathrm{~cm}$ (range: 9-14 cm) in females and $9.6 \mathrm{~cm}$ (range: $8-11 \mathrm{~cm}$ ) and $11.58 \mathrm{~cm}$ (range: $9-17 \mathrm{~cm}$ ) in males, respectively (-Table $\mathbf{2}$ ).

\section{Discussion}

Despite the importance of accurately identifying the peritoneal reflection in intraluminal rectal surgery, surgical management of rectal trauma secondary to penetrating trauma caused by gunshot wounds, stab wounds, impaling objects, and rectal adenocarcinoma amenable to neoadjuvant therapy, the precise location of the peritoneal reflection has not been extensively studied.

Najarian et al. ${ }^{12}$ investigated the location of the peritoneal reflection in 50 patients undergoing laparotomy. Similarly to the current study, the distance from the peritoneal reflection to the anal verge was measured via intraoperative proctoscopy and intra-abdominal visualization of the peritoneal reflection after laparotomy.

In that study, the mean lengths of the anterior peritoneal reflection were $9.0 \mathrm{~cm}$ and $9.7 \mathrm{~cm}$ in females and males, respectively, and the difference between genders was not statistically significant. Even though the distance to the anal verge estimated during laparotomy in our study was longer, we also found no significant difference in the length of the peritoneal reflection between genders $(p=0.32)$ and there was substantial agreement between the measurements (Kappa $=0.66)$.

Yun et al. ${ }^{2}$ intraoperatively evaluated the surgical length of the rectum in 23 males (mean age, 59.4 years old) and 23 females (mean age, 55.9 years old). The length of the peritoneal reflection measured from the anal verge was
Table 2 Mean lengths $( \pm S D$ ) of the middle rectal valve and of the peritoneal reflection in male and female patients $(p=0.32)$

\begin{tabular}{|l|l|l|}
\hline & Males & Females \\
\hline Middle rectal valve & $9.6 \pm 1.09 \mathrm{~cm}$ & $9.53 \pm 1.12 \mathrm{~cm}$ \\
\hline Peritoneal reflection & $11.58 \pm 1.89 \mathrm{~cm}$ & $10.59 \pm 1.37 \mathrm{~cm}$ \\
\hline
\end{tabular}

Abbreviation: SD, standard deviation.

$8.8 \pm 2.2 \mathrm{~cm}$ in females and $8.1 \pm 1.7 \mathrm{~cm}$ in males $(p=0.263)$, and similar results were observed for mean age and length of the peritoneal reflection between genders in the present study.

The location of the peritoneal reflection has not been extensively studied in living patients. In our study, the peritoneal reflection was more caudal in obese patients, which can be explained by the considerably higher intraabdominal pressures in these patients, especially morbidly obese ones, compared with nonobese adults. ${ }^{13-16}$ However, unlike our study, Yun et al. ${ }^{2}$ found no direct correlation between peritoneal reflection and BMI.

Ballard et al. ${ }^{16}$ showed that the intra-abdominal pressure is between $\sim 5$ and $7 \mathrm{mmHg}$ in nonobese adults and between $\sim 9$ and $14 \mathrm{~mm} \mathrm{Hg}$ in morbidly obese patients. Moreover, it has been shown that obesity is a potentially modifiable risk factor for pelvic organ prolapse and that this risk is increased by up to 2.5 times in patients with BMI $>30 \mathrm{~kg} / \mathrm{m}^{2} .^{17-19}$

The high intra-abdominal pressure combined with the reduced external anal sphincter tone may explain the increased prevalence of inadvertent escape of flatus and feces observed in class II and III morbidly obese patients referred to bariatric surgery, as demonstrated by Neto et al. ${ }^{20}$ Thus, our findings support previous research showing that obesity is a statistically significant direct or indirect risk factor for pelvic floor dysfunction in a population whose prevalence rates of obesity have greatly increased worldwide in the last decades. $^{21}$

Chengyu et al. ${ }^{6}$ reported that the anterior peritoneal reflection is lower in obese women, especially in those who are short, because the fat accumulation makes the mesorectum thick and the peritoneum at the anterior and lateral walls hangs loosely into the pelvic cavity.

Another interesting finding of our study was the more caudal location of the peritoneal reflection in women with higher parity; the peritoneal reflection was significantly lower in women with $>2$ deliveries than in women with $<2$ deliveries ( $p=0.009$ ); also, through a search in PubMed with the term anterior peritoneal reflection, no article was found correlating BMI and parity with this anatomical repair.

The substantial agreement between the lengths of the middle rectal valve and of the peritoneal reflection is of clinical significance, especially in cases in which these anatomical landmarks may affect the choice of treatment modality in penetrating trauma caused by stab wounds, gunshot wounds and impaling objects, cancer in the middle rectum, and clinical situations in which visualization is limited on imaging exams, particularly magnetic resonance imaging (MRI) of the pelvis. 
Yiqun et al. ${ }^{11}$ evaluated the usefulness of MRI in the staging of rectal cancers in 283 patients and found that the mean distance from the anal verge to the peritoneal reflection was $10.4 \pm 1.1 \mathrm{~cm}$ in females and $10.0 \pm 1.2 \mathrm{~cm}$ in males. The authors reported that the accuracy of predicting the location of the rectal tumor in relation to the peritoneal reflection was of $83 \%$, and of $98.2 \%$ in patients with a tumor located below the peritoneal reflection.

A substantial agreement was found between the Kappa value of the location in relation to the anterior peritoneal reflection determined by MRI and intraoperative findings $($ Kappa $=0.678)$. In addition, visualization of the anterior peritoneal reflection was affected by age $(p=0.049)$, thickness of the subcutaneous fat $(p=0.002)$, filling of the bladder $(p=0.001)$, and the uterine position in females $(p=0.001){ }^{11}$

Paparo et al. ${ }^{22}$ compared the diagnostic performance of MRI with rigid rectoscopy in assessing the location of intraand extraperitoneal rectal cancers using the findings obtained during abdominal surgery as the reference standard. The sensitivity and specificity were $98.15 \%$ and $100 \%$, respectively, for MRI, and $100 \%$ and $76.92 \%$, respectively, for rigid rectoscopy. The authors concluded that rigid rectoscopy is still the main means of assessing the level of a rectal tumor from the anal verge, but MRI has value in determining the level of the tumor in relation to the peritoneal reflection.

The length of the middle rectal valve and, therefore, the anatomy of the rectum, can also be determined with either flexible colonoscopy or sigmoidoscopy. Tanaka et al. ${ }^{23}$ determined the accuracy of flexible colonoscopy in assessing the height of the distal edge of rectal cancer from the anal verge in 173 patients with rectal adenocarcinoma and compared the results with those of rigid proctoscopy. The authors found that flexible colonoscopy provided remarkably similar tumor locations to those measured by rigid proctoscopy $(p=0.001)$.

The main limitations of our study were the small number of patients and the lack of postoperative anal ultrasound and anorectal manometry studies in patients with a more caudal peritoneal reflection, which could have provided not only topographic but also functional and anorectal anatomy information. Nevertheless, our findings provide further evidence that obesity and parity are anatomical risk factors for pelvic floor dysfunction that affect the location of the peritoneal reflection, concurrently with advanced age, estrogen deficiency, diabetes mellitus, pelvic radiotherapy, and orifice surgery, ${ }^{24-27}$ although we found no significant correlations between the length of the peritoneal reflection and classical risk factors associated with the location of this important surgical anatomical landmark, such as female gender and patient height. Moreover, and importantly, we used a standardized protocol in living patients rather than in cadavers, unlike most anatomy studies.

\section{Conclusion}

In our study, it was observed that there was substantial agreement between the lengths of the peritoneal reflection and of the middle rectal valve, and that the peritoneal reflection was significantly lower in overweight patients and in females with more than two vaginal deliveries.

Conflict of Interests

The authors have no conflict of interests to declare.

\section{References}

1 Wolff BG, Fleshman JW, Beck DE, Pemberton JH, Wexner SD. The ASCRS textbook of colon and rectal surgery. New York: Springer; 2007

2 Yun HR, Chun HK, Lee WS, Cho YB, Yun SH, Lee WY. Intraoperative measurement of surgical lengths of the rectum and the peritoneal reflection in Korean. J Korean Med Sci 2008;23(06): 999-1004

3 Dujovny N, Quiros RM, Saclarides TJ. Anorectal anatomy and embryology. Surg Oncol Clin N Am 2004;13(02):277-293

4 Corman ML. Colon and Rectal Surgery, 5th Ed. 2005:500-53

5 Salerno G, Sinnatamby C, Branagan G, Daniels IR, Heald RJ, Moran BJ. Defining the rectum: surgically, radiologically and anatomically. Colorectal Dis 2006;8(Suppl 3):5-9

6 Chengyu L, Xiaoxin J, Jian Z, Chen G, Qi Y. The anatomical significance and techniques of laparoscopic rectal surgery. Surg Endosc 2006;20(05):734-738

7 Gordon PH. Principles and Practice of Surgery for the Colon, Rectum and Anus. $3^{\text {rd }}$ ed. New York: Informa Healthcare; 1992

8 Abramson DJ. The valves of Houston in adults. Am J Surg 1978;136 (03):334-336

9 Nougaret S, Reinhold C, Mikhael HW, Rouanet P, Bibeau F, Brown $G$. The use of MR imaging in treatment planning for patients with rectal carcinoma: have you checked the "DISTANCE"? Radiology 2013;268(02):330-344

10 Tyler JA, Welling DR. Historical Perspectives on Colorectal Trauma Management. Clin Colon Rectal Surg 2018;31(01):5-10

11 Yiqun S, Tong T, Fangqi L, et al. Recognition of Anterior Peritoneal Reflections and Their Relationship With Rectal Tumors Using Rectal Magnetic Resonance Imaging. Medicine (Baltimore) 2016;95(09):e2889

12 Najarian MM, Belzer GE, Cogbill TH, Mathiason MA. Determination of the peritoneal reflection using intraoperative proctoscopy. Dis Colon Rectum 2004;47(12):2080-2085

13 Cummings JM, Rodning CB. Urinary stress incontinence among obese women: review of pathophysiology therapy. Int Urogynecol J Pelvic Floor Dysfunct 2000;11(01):41-44

14 Wasserberg N, Haney M, Petrone P, et al. Fecal incontinence among morbid obese women seeking for weight loss surgery: an underappreciated association with adverse impact on quality of life. Int J Colorectal Dis 2008;23(05):493-497

15 De Keulenaer BL, De Waele JJ, Powell B, Malbrain ML. What is normal intra-abdominal pressure and how is it affected by positioning, body mass and positive end-expiratory pressure? Intensive Care Med 2009;35(06):969-976

16 Ballard AC, Richter HE. The impact of obesity and weigth loss on urinary and bowel incontinence symptoms in women. Menopausal Med 2011;19(03):S1-S7

17 Giri A, Hartmann KE, Hellwege JN, Velez Edwards DR, Edwards TL. Obesity and pelvic organ prolapse: a systematic review and metaanalysis of observational studies. Am J Obstet Gynecol 2017;217 (01):11-26.e3

18 Nygaard I, Barber MD, Burgio KL, et al; Pelvic Floor Disorders Network. Prevalence of symptomatic pelvic floor disorders in US women. JAMA 2008;300(11):1311-1316

19 Swift S, Woodman P, O’Boyle A, et al. Pelvic Organ Support Study (POSST): the distribution, clinical definition, and epidemiologic condition of pelvic organ support defects. Am J Obstet Gynecol 2005;192(03):795-806 
20 Neto IJFC, Pinto RA, Jorge JMN, et al. Are Obese Patients at an Increased Risk of Pelvic Floor Dysfunction Compared to Nonobese Patients? Obes Surg 2017;27(07):1822-1827

21 Szczesny W, Bodnar M, Dabrowiecki S, Szmytkowski J, Marszałek A. Histologic and immunohistochemical studies of rectus sheath in obese patients. J Surg Res 2013;180(02):260-265

22 Paparo F, Puppo C, Montale A, et al. Comparison between magnetic resonance imaging and rigid rectoscopy in the preoperative identification of intra- and extraperitoneal rectal cancer. Colorectal Dis 2014;16(11):0379-0385

23 Tanaka A, Sadahiro S, Suzuki T, Okada K, Saito G. Comparisons of Rigid Proctoscopy, Flexible Colonoscopy, and Digital Rectal Examination for Determining the Localization of Rectal Cancers. Dis Colon Rectum 2018;61(02):202-206
24 Bø K Urinary incontinence, pelvic floor dysfunction, exercise and sport. Sports Med 2004;34(07):451-464

25 Richter HE, Burgio KL, Brubaker L, et al; Urinary Incontinence Treatment Network. Factors associated with incontinence frequency in a surgical cohort of stress incontinent women. Am J Obstet Gynecol 2005;193(06):2088-2093

26 Almeida MBA, Barra AA, Figueiredo EM, Velloso FSB, Silva AL, Monteiro MVC, Rodrigues AM. Disfunções de assoalho pélvico em atletas. Femina 2011;39(08):395-402

27 Reginelli A, Di Grezia G, Gatta G, et al. Role of conventional radiology and MRi defecography of pelvic floor hernias. BMC Surg 2013;13(Suppl 2):S53-S60 